\title{
Spillover Effects of Analyst Recommendations in the Banking Industry
}

\author{
Arjan Premti \\ University of Wisconsin- Whitewater \\ Luis Garcia-Feijoo \\ Florida Atlantic University \\ Jeff Madura \\ Florida Atlantic University
}

We find that analyst recommendations of banks result in spillover effects on the rival banks. The rival banks react is in the same direction as the rated bank, and the spillover effect depends on the rival's characteristics. These results suggest that the spillover effects in the banking industry are contagious and informed. The contagion effect is greater for riskier rivals and recommendations issued during riskier periods. Regulations that increased bank risk also increased the contagion of analyst recommendations. The contagion effect is greater for larger rivals and rivals with larger analyst following. The contagion effect is greater for positive recommendations.

Keywords: Analyst Recommendations, Spillover Effect, Contagion Effect, Informed Contagion, Bank Risk

\section{INTRODUCTION}

Studies have shown that analyst recommendations provide new information, elicit an immediate reaction in stock prices (Givoly and Lakonishok, 1979; Francis and Soffer, 1997; and Moshirian, Ng, and $\mathrm{Wu}, 2009$; Premti, Garcia-Feijoo, and Madura, 2017), and are useful in guiding investors' long term decisions (Womack, 1996; Boni and Womack, 2006; Premti, Garcia-Feijoo, and Madura, 2018). Analysts may also provide information about the industry, as their recommendations are often dependent on industry conditions (Piotroski and Roulstone, 2004; Akhigbe, Madura, and Newman, 2006; Liu, 2011). Therefore, an analyst recommendation may also provide new information about the firm's competitors and may result in a significant reaction in their stock price. This transfer of information from one firm to its competitors is generally known as the spillover effect.

The spillover effect has been observed in all industries; however, most spillover studies focus on banking. Kaufman (1994) reviews a large body of literature and concludes that the banking industry is more susceptible to spillover effects. Specifically, Kaufman (1994) shows that spillover effects are more likely to occur, spread faster; and have more serious consequences when they occur in the banking industry; they can result in larger losses, and subsequently spread to other industries. However, Milunovich and Tan (2013) find that, compared to the other industries, the financial sector exhibits fewer 
contagion instances in crisis and noncrisis periods. Most of the existing literature focuses on the spillover effect of negative news in the banking industry; however, little is known about the spillover effects of positive news in the banking industry. Ismailescu and Kazemi (2010) study the spillover effect of sovereign debt rating changes and find that positive rating changes have greater spillover effects compared to negative rating changes.

This paper focuses on the spillover effect of analyst recommendations in the banking industry. Analyst recommendations allow us to analyze the spillover effects of positive news in the banking industry and compare them to the spillover effects of negative news. Understanding the spillover effects of positive news in the banking industry is important for at least two reasons. First, a better understanding can have important policy implications, especially in cases when regulators want to strengthen or rescue the banking industry (e.g., during the financial crisis of 2008). Second, as investment opportunities associated with analyst recommendations dissipate very quickly (e.g., see Kim, Lin, and Slovin, 1997; or Busse and Green 2002), a better understanding of the spillover effects can help investors to take full advantage of investment opportunities created by analyst recommendations.

Akhigbe, Madura, and Newman (2006) examine the spillover effect of analyst recommendations in several industries; however, the results of this study are not directly applicable to the banking industry. First, banks have several characteristics that make them more susceptible to spillover effects: banks are highly leveraged, which makes them riskier and more sensitive to news; the products of different banks are very similar, making the banking industry very homogenous compared to other industries; and the banking industry is very opaque (e.g. see Morgan, 2002; or Iannotta, 2006), making it difficult for investors to distinguish banks from one another. Second, studies have shown that the banking industry is unique, and it behaves significantly different when it comes to news signals such as earnings announcements, earnings guidance, dividend changes, equity issues, share repurchases, etc. ${ }^{1}$

Prior literature has identified several types of spillover effects. The spillover effect could be contagious (in which the rival banks are affected in the same direction as the rated bank) or competitive (in which the rival banks are affected in the opposite direction of the rated bank). Aharony and Swary (1996) also show that the spillover effect could be informed (in which the effect of the rival bank depends on the rival's characteristics) or uninformed (in which all rival banks are affected in the same magnitude, regardless of their characteristics). This paper examines whether analyst recommendations in the banking industry result in spillover effects and, if so, whether these spillover effects are contagious/competitive and informed/uninformed.

This paper finds that both positive and negative recommendations result in spillover effects on rival banks. The price reaction of rival banks is in the same direction as the price reaction of the rated bank, and its magnitude is between $14 \%$ to $17 \%$ of the reaction of the rated bank. Thus, on average, analyst recommendations in the banking industry are contagious to rival banks.

This paper also finds that analyst recommendations result in greater spillover effects for riskier rivals and during riskier periods (periods with higher implied market volatility). Furthermore, regulations that increased the risk of the banking industry (such as Gramm-Leach-Bliley Act) resulted in greater spillover effects, while regulations that reduced the risk of the banking industry (such as Dodd-Frank Act) resulted in less pronounced spillover effects. These results suggest that investors in the banking industry rely more on information provided by the analysts when there is more uncertainty about the valuation of rival banks.

Analyst recommendations also result in greater spillover effects for larger rivals or rivals with greater analyst following. These results suggest that when investors receive a positive (negative) signal from an analyst of another bank, they buy (sell) the stock of the better-known (larger) rivals, or of the rivals that are more likely to receive a positive (negative) recommendation in the near future (rivals with greater analyst following). Furthermore, analyst recommendations result in greater spillover effects for the closest competitors, which further supports the hypothesis that the spillover effect of analyst recommendations in the banking industry is contagious and not competitive.

Additionally, this paper finds that positive recommendations lead to greater spillover effects than negative recommendations. This result is somewhat surprising as prior evidence has suggested that bank investors tend to panic and over-react to negative news; however, there are at least two reasons that can 
explain this result. First, the number of investors who can act upon a positive recommendation of another bank (i.e., buy the rival's stock) is larger than the number investors who can act upon a negative recommendation (i.e., short the rival's stock). Second, negative analyst recommendations are relatively minor events compared to the ones explored by the prior literature (e.g., bank failures); and thus, they are less likely to trigger large contagious effects.

Overall, we conclude analyst recommendations in the banking industry are characterized by an informed contagion spillover effect.

\section{LITERATURE REVIEW}

The literature on spillover effects has emphasized two dual-sided hypotheses: contagion effects versus competitive effects, and informed versus uninformed contagion.

\section{Contagion Versus Competitive Effects}

When a news event affects the rival firms in the same direction as it affects the event firm, the spillover effect is contagious; while, when a news event affects the rivals in the opposite direction that it affects the event firm, the spillover effect is competitive. Several studies have documented the existence of competitive and contagion effects. Slovin, Sushka, and Polonchek (1999) find that dividend reductions of money center banks have contagion effects, while the dividend reductions of regional banks have competitive effects on rival banks. Cornett, McNutt, and Tehranian (2005) examine the long-term performance of rival banks following the failure of several banks. They find that if the bank failure is due to a firm-specific problem, the performance of the rivals increases; however, if the failure is due to a general economic decline, the long-term performance of rivals decreases. Hertzel and Officer (2012) find that corporate loans originated or renegotiated within two years from the bankruptcy of a rival firm have higher yields; however, this effect is mitigated in concentrated industries. Hsu, Mamun, and Rose (2010) examine the spillover effects of loan rating downgrades and find that smaller competitors react negatively (contagion effect) while the larger competitors react positively (competitive effect). Although unrelated to the banking industry, Akhigbe, Madura, and Newman (2006) find that analyst recommendations exhibit both contagion and competitive based effects.

\section{Informed Versus Uninformed Spillover Effect}

When a news event affects all rivals to the same degree, regardless of their characteristics, the spillover effect is known as uninformed (or pure-panic); while, when a news event affects rivals differently, depending on the rivals' characteristics, the spillover effect is known as informed. Most of the findings of prior literature have been consistent with the informed spillover effect. Grammatikos and Saunders (1990) examine the spillover effects of the announcement of Citicorp's loan-loss reserves in 1987. They find that bank size was a significant determinant of this contagion effect. Aharony and Swary (1996) examine the contagion effect of five bank failures in the Southwest region. They find that rival banks that operated near the failed banks and the ones with the lowest capital experienced the lowest abnormal returns. Docking, Hirschey, and Jones (1997) find that the loan-loss reserve announcements of banks trigger negative shocks in the money center and regional banks. They also find that the size and the loan loss reserves of rival banks were a significant determinant of this contagion effect. Bessler and Nohel (2000) find that dividend cuts in money center banks cause negative shocks in all other banks. The effect is larger for non-announcing money center banks. Akhigbe and Madura (2001) asses the contagion effect of 99 bank failures and find that these failures transmit negative shocks to the rival banks. They find that these contagion effects vary over time and by the capital level of the rival bank. Helwege and Zhang (2016) examine troubled financial firms and find that counterparty contagion is greater for riskier firms. 


\section{HYPOTHESES}

\section{Contagion Versus Competitive Effect}

Analysts not only provide information about the rated bank, but they also provide information about the industry as their recommendations are often dependent on industry conditions (Piotroski and Roulstone, 2004; Akhigbe, Madura, and Newman, 2006; Liu, 2011). Therefore, a positive (negative) recommendation may signal positive (negative) prospects for the whole industry, and thus, it would be perceived as positive (negative) news for the rival banks. In addition, a positive (negative) recommendation may increase the likelihood that a competitor bank may receive a positive (negative) recommendation in the near future, and it may drive investors to take positions in anticipation of such recommendations. These arguments would suggest that analyst recommendations in the banking industry are subject to contagion effects (i.e., they affect the rival banks in the same direction as they affect the rated bank). However, Boni and Womack (2006) find that analyst recommendations are particularly valuable in ranking stocks within industries. In this context, a positive (negative) recommendation would suggest that the rated bank is in a better (worse) competitive position than its rivals, and hence it would signal negative (positive) news for the rival banks. This argument would suggest that analyst recommendations in the banking industry are subject to competitive effects (i.e., they affect the rival banks in the opposite direction that they affect the rated bank). Therefore, whether spillover effects in the banking industry are contagious or competitive is an open question, which this paper investigates.

\section{Informed Versus Uninformed Spillover Effect}

Several studies ${ }^{2}$ have investigated whether the spillover effects in the banking industry are informed (in which the spillover effect on each rival is conditioned on the rival's characteristics) or uninformed (i.e., pure panic- in which all rivals are affected to the same degree, regardless of their characteristics). To examine the spillover effect of analyst recommendations, we draw from prior literature and test whether several rival bank, time period, and analyst characteristics significantly affect the spillover effect. We conjecture that if the spillover effect is contingent upon these characteristics, then the spillover effect is informed, and vice versa. For expositional purposes, we group these characteristics into intuitive categories.

\section{Impact of Risk on the Degree of Spillover Effect}

When the level of risk is high, investors may face greater difficulty in assessing the values of the rival banks, and they may be more sensitive to any information, including analyst recommendations of other banks. Additionally, when a bank receives a positive (negative) recommendation, investors would benefit the most by buying (selling) the rivals that are more sensitive to news, hence the riskier rivals. These arguments would suggest a greater contagion effect for the rivals with greater risk.

Conversely, investors may view riskier rivals as unique. They may realize that any information provided by analysts of other banks does not apply to the riskier rivals, and they may rely less on analyst recommendations of other banks. This argument would suggest a lesser contagion effect for the rivals with greater risk. To measure the effect of risk on the spillover effect of analyst recommendations, we follow Premti, Garcia-Feijoo, and Madura (2017) and Premti, Garcia-Feijoo, and Madura (2018), and use the following variables:

\section{Rival's Standard Deviation of Returns}

The standard deviation of the rival's daily returns (STDEV) in the 6-month period prior to the announcement is used to measure the total risk of the rival bank.

\section{Rival's Beta}

The rival's beta (BETA) measures its degree of systematic risk. Akhigbe, Madura, Newman (2006) find that firms with greater beta exhibit greater contagion effects resulting from analyst recommendations. 
BETA of rival banks is measured by using the market model in the window $(-365,-30)$ prior to the recommendation.

\section{Rival's Capital Ratio}

The rival's capital ratio (CAPR) is another measure of bank risk. Akhigbe and Madura (2001), Cornett, McNutt, and Tehranian (2005), and Aharony and Swary (1996), Bruyckere et al. (2013), and Dungey and Gajurel (2015) find that banks with lower capital ratios exhibit greater contagion effects. CAPR is measured as the sum of Tier 1 and Tier 2 capital of the rival bank.

\section{Implied Market Volatility}

The VIX index (VIX) captures the degree of risk and uncertainty that exists in the market. VIX is measured as the level of the VIX index in the day of the analyst's recommendation.

\section{Gramm-Leach-Bliley Act}

The Gramm-Leach-Bliley Act (GRAMM) of 1999 allowed banks to merge with investment banks and insurance companies. Several studies have shown that GRAMM increased risk of the banking industry. ${ }^{3}$ To measure the spillover effect of analyst recommendations in the riskier, post-GRAMM period, we use a dummy variable that takes the value of 1 after November 12, 1999, and 0 otherwise.

\section{Dodd-Frank Act}

On July 21, 2010, in response to the financial crisis, the Dodd-Frank Act (DODD) was passed, aiming to create a safer banking industry. Studies show that some provisions of the DODD reduced the risk of the banking industry. ${ }^{4}$ To measure the spillover effect of analyst recommendations in the less risky, postDODD period, we use a dummy variable that takes the value of 1 after July 21, 2010, and 0 otherwise.

\section{Impact of Other Rival, Analyst, and Time Period Characteristics}

\section{Rival's Analyst Following (AnalystFollowing)}

Studies show that analyst information is reflected very quickly into stock prices ${ }^{5}$, and typical investors may be unable to benefit from it. However, they may try to benefit by anticipating the next bank that is likely to receive a recommendation. Therefore, investors may target the rivals with a large analyst following because they would have a higher likelihood of receiving a recommendation in the same direction as the current recommendation. This argument would suggest a greater contagion effect for rivals with greater analyst following. Similar to Premti, Garcia-Feijoo, and Madura (2017) and Premti, Garcia-Feijoo, and Madura (2018), AnalystFollowing is calculated as the number of analysts that have issued a recommendation for the rival bank in the same calendar year.

\section{The Rival's Size (SIZE)}

If analyst recommendations result in a contagion effect, they do so because they drive investors to look for profitable opportunities in other banks. Investors would be more likely to recall (or to identify as rivals) banks which have larger name recognition. We use SIZE as a proxy for the bank's name recognition, as larger banks tend to be better-known. The name recognition hypothesis would suggest that the contagion effects should be more pronounced for larger banks. Prior literature has found mixed results on the effect of size on the contagion effect. Akhigbe and Madura (2001) find that smaller rival banks are subject to greater contagion effects of bank failures. However, Aharony and Swary (1996) find that larger rivals are subject to greater contagion effects of bank failures. SIZE is measured as the natural logarithm of the rival's total assets.

\section{Rival's Non-interest Income}

The rival's non-interest income (NII) is used as a proxy for the rival's involvement in non-traditional banking activities. Rivals with high NII tend to be more complex institutions. As a result, their investors 
may be eager for information and may rely more on the recommendations of other banks. NII is measured as the rival's non-interest income divided by revenue.

\section{Recession Status}

Due to their high leverage, banks are highly susceptible to market conditions. During recessionary periods, bank failures are more common, and the banking industry suffers from greater panic. Loh and Stulz (2018) argue that during bad times, investors put a higher value on analyst research. They find that recommendations have a greater impact on stock prices during bad times. This argument would suggest greater spillover effects during recessionary periods. However, Loh and Stulz (2018) also show that analysts are more inaccurate, and their recommendations are noisier during bad times. This evidence would suggest lower spillover effects during recessionary periods. We measure the effect of recessionary periods by including a RECESSION dummy that equals 1 if the recommendation occurred during a recessionary period, as defined by the National Bureau of Economic Research, and 0 otherwise.

\section{Correlation of Returns between the Rival and the Rated Bank}

The correlation of returns (CORRELATION) between the rated bank and the rival bank prior to the recommendations captures of the degree of similarity between the rated bank and the rival. This variable could provide evidence for both of our sets of hypotheses: 1) If the spillover effect of analyst recommendations is informed, then the degree of similarity between the two banks should influence the spillover effect. 2) Furthermore, if the spillover effect of analyst recommendations in the banking industry is contagious, then the closer rivals should be subject to greater spillover effects. If the spillover effect of analyst recommendations is competitive, then the closer rivals should be subject to lesser (or negative) spillover effects. CORRELATION is measured as the correlation of returns between the rated bank and the rival bank in the event window $(-365,-30)$.

\section{Global Analyst Research Settlement}

The Global Analyst Research Settlement (SETTLEMENT) was a settlement between the SEC and some of the largest US investment banks reached on April 29, 2003. The investment banks were forced to take steps to reduce the conflicts of interest in future recommendations. Hovakimian and Saenyasiri (2010) find that analyst bias decreased in the post-SETTLEMENT period. Given that recommendations may be more informative in the post-Settlement period, they may be subject to greater spillover effects. To capture the impact of the SETTLEMENT on the spillover effect of analyst recommendations, we use a dummy variable called SETTLEMENT that takes the value of 1 after April 29, 2003, and 0 otherwise.

\section{Analyst Experience}

The analyst experience (EXPERIENCE) captures analyst's quality and name recognition. Experienced analysts could issue more influential recommendations and may be able to exert greater influence on the rival banks. Following Premti, Garcia-Feijoo, and Madura (2017) and Premti, GarciaFeijoo, and Madura (2018), EXPERIENCE is measured as the logarithm of the number of days that the analyst has been in the IBES files on the day of the recommendation.

Number of Industries Covered by Analyst

The number of industries covered by the analyst (NrOfIndustries) captures the analyst's specialization. Analysts that cover fewer industries (i.e. only the banking industry) may issue recommendations that are informative about the banking industry. Following Premti, Garcia-Feijoo, and Madura (2017) and Premti, Garcia-Feijoo, and Madura (2018), NrOfIndustries is measured as the number of 4-digit SIC codes that the analyst covers.

\section{Valuation Effect on Rated Bank}

The abnormal return of the rated bank (RATEDCAR) captures the amount of information that the analyst provides for the rated bank. If an analyst issues a recommendation that provides a relatively high 
level of information for the rated bank, it should also provide more information for the rival banks. RATEDCAR is measured by the $\operatorname{CAR}(0,1)$ for the rated bank. Two types of benchmarks are used to calculate CAR01: the market model and the Fama-French-Carhart 4-factor model.

\section{Positive Dummy}

The positive dummy (POSITIVE) is a variable that takes the value of 1 if the recommendation was a positive one (a Buy/Strong Buy, or an upgrade to a Buy/Strong Buy, depending on the subsample) and 0 otherwise. It captures whether there is any difference in the magnitude of the spillover effects between positive and negative recommendations.

\section{DATA AND METHODS}

\section{Sample Selection and Methodology of Calculating Returns}

Following Akhigbe and Martin (2006), we study all commercial banks and savings institutions with the SIC codes $602 \mathrm{X}$ and $603 \mathrm{X}$. Bank data is collected from the Compustat Bank database, and analyst recommendations are collected from the IBES database in the time period 1994-2012. To calculate upgrades and downgrades correctly, we quantify recommendations using the following scale: Strong Buy $=5$, Buy $=4$, Hold=3, Sell=2, Strong Sell $=1$.

To test the spillover effects of analyst recommendations in the banking industry, the 10 closest rivals of each rated bank are selected by using the following methodology. Each rated bank is matched with all the banks that have the same four-digit SIC code. To ensure that the matched rivals are true competitors of the rated bank, we maintain in the sample only the rivals whose total assets are within $20 \%$ (larger or smaller) of the assets of the rated bank. If more than 10 banks fit these criteria, we maintain in the sample only the top ten competitors which have the highest correlation of returns with the rated bank in the event window $(-365,-30)$.

Loh and Stulz (2011) find that only $12 \%$ of the analyst recommendations provide new information for the rated firm. If a recommendation does not provide new information for the rated bank, it is unlikely to provide new information for the competitors of the rated bank. Therefore, we include in the sample only the analyst recommendations which provide new information and elicit a significant impact on the stock of the rated bank. Following the methodology of Loh and Stulz (2011) we maintain in the sample the recommendations whose announcement CAR is in the correct direction (positive for a positive recommendation or negative for a negative recommendation), and it is statistically significant (the absolute value of CAR is greater than $1.96 * \sqrt{2} * \sigma_{\varepsilon}$ where $\sigma_{\varepsilon}$ is the standard deviation of the residuals from a daily time-series regression of past three-months (trading days -69 to -6 ) of firm returns against market returns). Similar to Loh and Stulz (2011) we remove from our sample event days with multiple recommendations for the same bank ${ }^{6}$ and banks that had a share price less than $\$ 1$ in the day prior to the announcement.

To measure the impact of the analyst recommendations on the rival banks, we use the cumulative abnormal return (CAR) of the rival in the event window $(0,1)$. CARs are estimated by using the market model or the Fama-French-Carhart 4-factor model, and the model parameters are estimated in the event window $(-365,-30)$. To measure the spillover effect, we normalize the announcement return on the rival bank by dividing it with the announcement return of the rated bank. We call this ratio the SpilloverRatio, and it is calculated as:

SpilloverRatio $=\mathrm{CAR}_{\text {Rival }} / \mathrm{CAR}_{\text {Rated }}$

The SpilloverRatio measures the proportion of the analyst information that is transferred to the rival banks. It is our main variable of interest in the regression models because it standardizes the spillover effect and allows us to directly compare the spillover effect of positive and negative recommendations in a multivariate setting. ${ }^{7}$ However, in our univariate results, we also display the results with the CAR of the rival bank as a measure of the spillover effect. 


\section{Summary Statistics and Univariate Tests}

Table 1 displays the summary statistics for several characteristics of the rival banks. On average, the spillover effect, as measured by the SpilloverRatio, ranges between $13.59 \%$ and $16.87 \%$. This result suggests that, on average, between $14 \%$ and $17 \%$ of the analyst information affects the rival banks.

The standard deviation of returns of the rival bank in the 6-month period prior to analyst recommendations averages $2.1 \%$, and the average rival bank has a beta of 1.13 . The rival banks have an average capital ratio of $13.44 \%$. The VIX index for the sample period averages 20.79 . About $79.56 \%$ of the recommendations occur after GRAMM, $10.33 \%$ of the recommendations occur after the DODD, $63.69 \%$ of the recommendations occur after the SETTLEMENT, and $12.75 \%$ of the recommendations occur during a recession period. The average rival bank is followed by 4.26 analysts and AnalystFollowing ranges from 0 to 25 . The average rival bank has $\$ 16.5$ billion in assets and generates $20.05 \%$ of its income from non-interest sources. On average, the returns of the rival bank have $41.05 \%$ correlation with the returns of the rated bank in the year prior to the recommendation. On average, analysts of the rival banks have 1826 days of experience and cover 4.8 SIC codes. The full sample contains 12,569 observations.

TABLE 1 SAMPLE DESCRIPTION

\begin{tabular}{lccccc}
\hline Variable & $\mathrm{N}$ & Mean & STDEV & Min & Max \\
\hline SpilloverRatio & 12569 & 0.1687 & 0.5280 & -3.5135 & 10.5853 \\
SpilloverRatioFFC & 12568 & 0.1359 & 1.0707 & -12.1142 & 93.8128 \\
STDEV & 12569 & 0.0210 & 0.0126 & 0.0016 & 0.1418 \\
BETA & 12565 & 1.1312 & 0.5409 & -0.6200 & 2.9300 \\
CAPR & 12218 & 13.4443 & 2.7739 & -1.4400 & 42.9000 \\
VIX & 12569 & 20.7925 & 9.3245 & 9.4800 & 80.0600 \\
GRAMM & 12569 & 0.7956 & 0.4033 & 0 & 1 \\
DODD & 12569 & 0.1033 & 0.3043 & 0 & 1 \\
AnalystFollowing & 12569 & 4.2641 & 3.9838 & 0 & 25 \\
Total Assets & 12569 & 16500.4300 & 73399.6400 & 89.9600 & 2429252.0000 \\
SIZE & 12569 & 8.6402 & 1.2100 & 4.4994 & 14.7031 \\
NII & 11084 & 0.2005 & 0.1050 & -0.3491 & 0.6841 \\
RECESSION & 12569 & 0.1275 & 0.3336 & 0 & 1 \\
CORRELATION & 12569 & 0.4105 & 0.2314 & 0.0000 & 0.9324 \\
SETTLEMENT & 12569 & 0.6396 & 0.4801 & 0 & 1 \\
EXPERIENCE (days) & 12569 & 1825.8030 & 1464.1990 & 1 & 6898.9970 \\
Experience (Log) & 12569 & 7.0015 & 1.3767 & 0 & 8.8391 \\
NrOfIndustries & 12569 & 4.8056 & 19.3304 & 1 & 243.0000 \\
\hline
\end{tabular}

This table displays the summary statistics of the variables used in the regression models. SpilloverRatio is calculated as $\mathrm{CAR}_{\text {Rival }} / \mathrm{CAR}_{\text {Rated }}$ by using the market model. SpilloverRatioFFC is the SpilloverRatio calculated by using the Fama-French-Carhart 4-factor model. All the other variables are calculated as explained above.

Table 2 displays the average spillover effect for the rival banks, and the results of a series of t-tests of whether the spillover effect is significantly different from 0 . This table displays the results by each recommendation level. The first two columns display the results for the SpilloverRatio measured by using the market model (column 1) and by the Fama-French-Carhart 4-factor model (column 2). Columns 3 and 4 display the results for the CAR01 for the rival banks measured by using the market model (column 3) 
and by the Fama-French-Carhart 4-factor model (column 4). The SpilloverRatio ranges from 3.35\% to $19.69 \%$. It is always positive and significant at the $1 \%$ level in all measures, except for the SpilloverRatio measured by the Fama-French-Carhart 4-factor model (SpilloverRatioFFC) for the Strong Sell recommendations, which is insignificant. These results show that analyst recommendations have a significant impact on rival banks. The SpilloverRatio always being positive shows that, on average, the rival banks are affected in the same direction as the rated banks, which suggests that the spillover effect is contagious. The last two columns show that Hold, Sell, and Strong Sell recommendations result in significantly negative returns for the rival banks ranging from $-0.29 \%$ to $-1.57 \%$. Buy, and Strong Buy recommendations result in positive returns for the rival banks. The rival CAR01 ranges from $0.30 \%$ to $1.25 \%$ and it is statistically significant at the $1 \%$ level in all measures.

TABLE 2

TEST RESULTS OF THE SPILLOVER EFFECT BY THE RECOMMENDATION LEVEL

\begin{tabular}{llcccc}
\hline RecLevel & & SpilloverRatio & SpilloverRatioFFC & CARrival & CARrivalFFC \\
\hline Strong Sell & Average & $0.0974^{* * *}$ & 0.0335 & $-0.0078^{* * *}$ & $-0.0037^{* *}$ \\
& P-value & $(0.0000)$ & $(0.2039)$ & $(0.0000)$ & 0.0238 \\
& $\mathrm{~N}$ & 456 & 456 & 456 & 456 \\
\hline Sell & Average & $0.1969^{* * *}$ & $0.1474^{* * *}$ & $-0.0157^{* * *}$ & $-0.0103^{* * *}$ \\
& P-value & $(0.0000)$ & $(0.0000)$ & $(0.0000)$ & $(0.0000)$ \\
& $\mathrm{N}$ & 1025 & 1025 & 1025 & 1025 \\
\hline Hold & Average & $0.1744^{* * *}$ & $0.1339^{* * *}$ & $-0.0040^{* * *}$ & $-0.0029^{* * *}$ \\
& P-value & $(0.0000)$ & $(0.0000)$ & $(0.0000)$ & $(0.0000)$ \\
& $\mathrm{N}$ & 4714 & 4714 & 4714 & 4714 \\
\hline Buy & Average & $0.1648^{* * *}$ & $0.1615^{* * *}$ & $0.0049^{* * *}$ & $0.0030^{* * *}$ \\
& P-value & $(0.0000)$ & $(0.0000)$ & $(0.0000)$ & $(0.0000)$ \\
& $\mathrm{N}$ & 3581 & 3580 & 3581 & 3580 \\
\hline Strong Buy & Average & $0.1653^{* * *}$ & $0.1188^{* * *}$ & $0.0125^{* * *}$ & $0.0076^{* * *}$ \\
& P-value & $(0.0000)$ & $(0.0000)$ & $(0.0000)$ & $(0.0000)$ \\
& $\mathrm{N}$ & 2788 & 2788 & 2788 & 2788 \\
\hline Total & Average & 0.1687 & 0.1359 & 0.0011 & 0.0005 \\
& $\mathrm{~N}$ & 12564 & 12563 & 12564 & 12563 \\
\hline
\end{tabular}

This table displays the results of a series of t-tests which examine whether analyst recommendations result in spillover effects that are significantly different from 0 . The spillover effect is measured for each recommendation level. For each recommendation level, the top number is the average CAR01 or the average SpilloveRatio, while the numbers in brackets are the p-values of the t-test that examines whether the average CAR01 or the average SpilloveRatio are significantly different from $0 . *, *$, and $* * *$ represent the level of significance at the $10 \%, 5 \%$, and $1 \%$, respectively. The first two columns display the results of the SpilloverRatio. Columns 3 and 4 display the results of the rival CAR. In columns 1 and 3, the estimates are calculated by using the market model, while in columns 2 and 4, the estimates are calculated by using the Fama-French-Carhart 4-factor model as a benchmark.

Table 3 displays similar information to Table 2; however, unlike Table 2, which is partitioned by the recommendation level, Table 3 is partitioned by the change in the recommendation level by the same analyst (RecChange). RecChange can take values from -4 to 4 with the positive numbers representing upgrades and negative numbers representing downgrades. Table 3 shows that the SpilloverRatio is positive and significant (usually at the 1\% level) for 1-level and 2-level downgrades, analyst reiterations, and for 1-level, 2-level, and 3-level upgrades. These results further support the results of Table 2 and show that analyst recommendations have a significant contagious effect on the rival banks. Columns 3 
and 4 show that the rival CAR01 is negative and significant at the 1\% level for 1-level and 2-level downgrades, and it is positive and significant for reiterations, and 1-level, 2-level, and 3-level upgrades.

TABLE 3

TEST RESULTS OF THE SPILLOVER EFFECT BY THE LEVEL OF UPGRADE/DOWNGRADE

\begin{tabular}{|c|c|c|c|c|c|}
\hline RecChange & & SpilloverRatio & SpilloverRatioFFC & CARrival & CARrivalFFC \\
\hline \multirow[t]{3}{*}{-4} & Average & 0.0740 & 0.0574 & -0.0070 & -0.0048 \\
\hline & P-value & $(0.2272)$ & $(0.3461)$ & (0.5209) & $(0.6378)$ \\
\hline & $\mathrm{N}$ & 10 & 10 & 10 & 10 \\
\hline \multirow[t]{3}{*}{-3} & Average & -0.0176 & 0.0236 & 0.0024 & -0.0024 \\
\hline & P-value & $(0.7627)$ & $(0.6346)$ & $(0.7143)$ & $(0.6769)$ \\
\hline & $\mathrm{N}$ & 5 & 5 & 5 & 5 \\
\hline \multirow[t]{3}{*}{-2} & Average & $0.1247^{* * *}$ & $0.0786 * * *$ & $-0.0069 * * *$ & $-0.0042 * * *$ \\
\hline & P-value & $(0.0000)$ & $(0.0000)$ & $(0.0000)$ & $(0.0000)$ \\
\hline & $\mathrm{N}$ & 1781 & 1781 & 1781 & 1781 \\
\hline \multirow[t]{3}{*}{-1} & Average & $0.1739 * * *$ & $0.1424 * * *$ & $-0.0091^{* * *}$ & $-0.0058^{* * *}$ \\
\hline & P-value & $(0.0000)$ & $(0.0000)$ & $(0.0000)$ & $(0.0000)$ \\
\hline & $\mathrm{N}$ & 3199 & 3199 & 3199 & 3199 \\
\hline \multirow[t]{3}{*}{0} & Average & $0.2826 * * *$ & $0.3785^{* *}$ & $0.0167 * * *$ & $0.0085^{* * *}$ \\
\hline & P-value & $(0.0000)$ & $(0.0259)$ & $(0.0000)$ & $(0.0000)$ \\
\hline & $\mathrm{N}$ & 584 & 584 & 584 & 584 \\
\hline \multirow[t]{3}{*}{1} & Average & $0.1478 * * *$ & $0.1029 * * *$ & $0.0081 * * *$ & $0.0045^{* * *}$ \\
\hline & P-value & $(0.0000)$ & $(0.0000)$ & $(0.0000)$ & $(0.0000)$ \\
\hline & $\mathrm{N}$ & 2798 & 2798 & 2798 & 2798 \\
\hline \multirow[t]{3}{*}{2} & Average & $0.1809 * * *$ & $0.1348 * * *$ & $0.0137 * * *$ & $0.0091 * * *$ \\
\hline & P-value & $(0.0000)$ & $(0.0000)$ & $(0.0000)$ & $(0.0000)$ \\
\hline & $\mathrm{N}$ & 1672 & 1672 & 1672 & 1672 \\
\hline \multirow[t]{3}{*}{3} & Average & $0.1416 * * *$ & $0.0770 *$ & $0.0112 * * *$ & $0.0067^{* *}$ \\
\hline & P-value & $(0.0011)$ & $(0.0727)$ & $(0.0000)$ & $(0.0133)$ \\
\hline & $\mathrm{N}$ & 25 & 25 & 25 & 25 \\
\hline \multirow[t]{3}{*}{4} & Average & $0.3840 *$ & 0.3658416 & $0.1347^{*}$ & 0.1036 \\
\hline & P-value & $(0.0732)$ & $(0.1297)$ & $(0.0803)$ & (0.1218) \\
\hline & $\mathrm{N}$ & 11 & 11 & 11 & 11 \\
\hline \multirow[t]{2}{*}{ Total } & Average & 0.1654 & 0.1325 & 0.0015 & 0.0008 \\
\hline & $\mathrm{N}$ & 10085 & 10085 & 10085 & 10085 \\
\hline
\end{tabular}

This table displays the results of a series of t-tests which examine whether analyst recommendations result in spillover effects that are significantly different from 0 . The spillover effect is measured for each level of upgrade/downgrade. For each level of upgrade/downgrade, the top number is the average CAR01 or the average SpilloveRatio, while the numbers in brackets are the p-values of the t-test that examines whether the average CAR01 or the average SpilloveRatio are significantly different from $0 . *, * *$, and $* * *$ represent the level of significance at the $10 \%, 5 \%$, and $1 \%$, respectively. The first two columns display the results of the SpilloverRatio. Columns 3 and 4 display the results of the rival CAR. In columns 1 and 3, the estimates are calculated by using the market model, while in columns 2 and 4, the estimates are calculated by using the Fama-French-Carhart 4-factor model as a benchmark. 


\section{Methodology for the Cross-sectional Analysis}

To examine whether the spillover effect of analyst recommendations in the banking industry is informed or uninformed, we apply the following multivariate regression model:

SpilloverRatio $=\alpha+\beta_{1}$ STDEV $+\beta_{2}$ BETA $+\beta_{3}$ CAPR $+\beta_{4}$ VIX $+\beta_{5}$ GRAMM $+\beta_{6}$ DODD + $\beta_{7}$ AnalystFollowing (or SIZE) $+\beta_{8}$ NII $+\beta_{9}$ RECESSION $+\beta_{10}$ CORRELATION $+\beta_{11}$ SETTLEMENT + $\beta_{12}$ EXPERIENCE $+\beta_{13}$ NrOfIndustries $+\beta_{14}$ RATEDCAR $+\beta_{15}$ POSITIVE $+\varepsilon_{i}$

Because AnalystFollowing and SIZE are highly correlated, we run two versions of the model, each including only one of these two variables. After this adjustment, multicollinearity is no longer an issue as the highest VIF in our model is less than 3. Our model includes the variable POSITIVE, which allows us to capture the difference between the spillover effects of positive versus negative recommendations. The inclusion of this variable requires us to separate positive and negative recommendations; however, this separation requires some attention because any given recommendation could send mixed, positive and negative signals. Given that both, rating levels and rating changes provide new information to investors (Barber, Lehavy, and Trueman, 2010), a downgrade from a Strong Buy to a Buy could send a negative signal because it is a downgrade; however, it could also send a positive signal because it is still a Buy recommendation. Similarly, an upgrade into a Sell recommendation could send mixed messages to the investors. Cliff (2007) distinguishes between positive and negative recommendations by separating his sample into subsamples that contain only Buy or only Sell recommendations. Similar to Cliff (2007), we classify as positive recommendations that are either a Buy or a Strong Buy, and as negative recommendations that are either a Sell or a Strong Sell. To ensure the robustness of our results, we follow Premti, Garcia-Feijoo, and Madura (2017) and also use a stricter classification method in which we classify as positive the recommendations that are an upgrade to Buy or an upgrade to Strong Buy recommendation, and as negative the recommendations that are a downgrade to a Sell or a downgrade to a Strong Sell recommendation.

\section{RESULTS}

Table 4 displays the results of the multivariate regression model applied to the subsample that contains recommendations that are a Buy, a Strong Buy, a Sell, or a Strong Sell. Models 1 and 2 include the AnalystFollowing variable, while models 3 and 4 include the SIZE variable. In models 1 and 3, the dependent variable is the SpilloverRatio calculated by using the market model, while in models 2 and 4, the dependent variable is the SpilloverRatio calculated by using the Fama-French-Carhart 4-factor model. The R-squared of the models in Table 4 ranges from $3.8 \%$ to $7 \%$.

Table 4 shows that the coefficient of STDEV is positive and significant in all four models. This result shows that rival banks with higher STDEV (riskier banks) are subject to greater contagion effects. It supports the informed spillover hypothesis, and it suggests that when a bank receives a positive (negative) recommendation, investors will benefit the most by buying (selling) the rivals that are more sensitive to news, hence the riskier rivals. This result is further supported by the coefficients of BETA (always positive and it is significant in two of the models) and CAPR (always negative and it is significant in two of the models). These results also show that riskier banks (banks with higher betas or banks with lower capital ratios) are subject to greater contagion effects.

Similarly, the coefficients of VIX (positive), GRAMM (positive), and DODD (negative) are significant in all models and further support the informed spillover hypothesis. They suggest that the contagion effect is greater during riskier periods (when the VIX is higher or after the enactment of the Gramm-Leach-Bliley Act which increased the risk of the banking industry), and lower during a less risky period (after the enactment of the Dodd-Frank Act which lowered the risk of the banking industry).

The coefficient of AnalystFollowing is positive and significant in both models. This result further supports the informed spillover hypothesis and suggests that analyst recommendations result in greater contagion effects in rivals with greater analyst coverage. Given prior evidence that analyst information is 
reflected very quickly into prices (see Kim, Lin, and Slovin, 1997 and Busse and Green, 2002), investors may try to benefit by investing in the rivals that are more likely to receive a recommendation, the ones with greater analyst following. This result also suggests that investors may try to benefit by investing in the rival banks that they can easily recall or recognize. Banks with greater analyst coverage receive greater publicity, and investors may recognize them more easily as competitors of the rated bank. This latter explanation is also supported by the coefficient of SIZE. The coefficient of SIZE is positive and significant in both models, and it shows that the contagion effect is greater for larger rivals. This result further supports the informed hypothesis and suggests that investors may try to take advantage of analyst information by investing in the rival banks that tend to receive more publicity and tend to have greater name recognition (the larger rivals).

TABLE 4

\section{RESULTS OF THE REGRESSION MODEL APPLIED TO THE SUBSAMPLE THAT CONTAINS ONLY BUY OR SELL RECOMMENDATIONS}

\begin{tabular}{|c|c|c|c|c|}
\hline & Model 1 & Model 2 & Model 3 & Model 4 \\
\hline & \multicolumn{4}{|c|}{ SpilloverRatio SpilloverRatioFFCSpilloverRatioSpilloverRatioFFC } \\
\hline \multirow[t]{2}{*}{ CONSTANT } & $-0.236^{* * *}$ & $-0.199 * * *$ & $-0.614^{* * *}$ & $-0.551^{* * *}$ \\
\hline & $(-4.05)$ & $(-2.94)$ & $(-7.93)$ & $(-6.10)$ \\
\hline \multirow[t]{2}{*}{ STDEV } & $1.748 * * *$ & $1.611^{* *}$ & $2.027^{* * *}$ & $1.858^{* *}$ \\
\hline & $(2.76)$ & $(2.16)$ & $(3.20)$ & $(2.49)$ \\
\hline \multirow[t]{2}{*}{ BETA } & $0.0531 * * *$ & 0.0152 & $0.0563^{* * *}$ & 0.018 \\
\hline & (3.25) & $(0.79)$ & $(3.45)$ & (0.94) \\
\hline \multirow[t]{2}{*}{ CAPR } & $-0.00422 *$ & $-0.00499 *$ & -0.00252 & -0.00343 \\
\hline & $(-1.75)$ & $(-1.76)$ & $(-1.04)$ & $(-1.20)$ \\
\hline \multirow[t]{2}{*}{ VIX } & $0.00542^{* * *}$ & $0.00584^{* * *}$ & $0.00502^{* * *}$ & $0.00548^{* * *}$ \\
\hline & (5.79) & $(5.33)$ & $(5.36)$ & (4.99) \\
\hline \multirow[t]{2}{*}{ GRAMM } & $0.106 * * *$ & $0.0766 * *$ & $0.107 * * *$ & $0.0771 * *$ \\
\hline & (3.94) & $(2.42)$ & (3.96) & (2.44) \\
\hline \multirow[t]{2}{*}{ DODD } & $-0.156 * * *$ & $-0.170^{* * *}$ & $-0.145^{* * *}$ & $-0.159 * * *$ \\
\hline & $(-6.94)$ & $(-6.45)$ & $(-6.44)$ & $(-6.04)$ \\
\hline \multirow[t]{2}{*}{ AnalystFollowing } & $0.0118^{* * *}$ & $0.0113^{* * *}$ & & \\
\hline & $(6.07)$ & $(4.97)$ & & \\
\hline \multirow[t]{2}{*}{ SIZE } & & & $0.0553^{* * *}$ & $0.0517^{* * *}$ \\
\hline & & & (7.96) & (6.34) \\
\hline \multirow[t]{2}{*}{ NII } & 0.0377 & 0.0299 & -0.0851 & -0.0826 \\
\hline & $(0.54)$ & $(0.37)$ & $(-1.17)$ & $(-0.97)$ \\
\hline \multirow[t]{2}{*}{ RECESSION } & $-0.0545^{* *}$ & $-0.0944^{* * *}$ & $-0.0628 * * *$ & $-0.102 * * *$ \\
\hline & $(-2.38)$ & $(-3.52)$ & $(-2.77)$ & $(-3.85)$ \\
\hline \multirow[t]{2}{*}{ CORRELATION } & $0.313^{* * *}$ & $0.265 * * *$ & $0.241 * * *$ & $0.201 * * *$ \\
\hline & $(7.54)$ & $(5.46)$ & (5.54) & (3.93) \\
\hline \multirow[t]{2}{*}{ SETTLEMENT } & -0.0181 & 0.0286 & -0.0132 & 0.0327 \\
\hline & $(-0.80)$ & (1.08) & $(-0.58)$ & (1.24) \\
\hline \multirow[t]{2}{*}{ EXPERIENCE } & $-0.00863^{*}$ & $-0.0116^{*}$ & $-0.0108 * *$ & $-0.0136 * *$ \\
\hline & $(-1.70)$ & $(-1.95)$ & $(-2.14)$ & $(-2.29)$ \\
\hline \multirow[t]{2}{*}{ NrOfIndustries } & 0.000517 & 0.000519 & 0.00057 & 0.000568 \\
\hline & (1.36) & $(1.16)$ & $(1.50)$ & $(1.27)$ \\
\hline \multirow[t]{2}{*}{ RATEDCAR } & $-0.214^{* *}$ & $-0.337 * * *$ & $-0.212^{* *}$ & $-0.324 * *$ \\
\hline & $(-1.99)$ & $(-2.61)$ & $(-1.98)$ & $(-2.52)$ \\
\hline \multirow[t]{2}{*}{ POSITIVE } & $0.0766 * * *$ & $0.104 * * *$ & $0.0712 * * *$ & $0.0967 * * *$ \\
\hline & $(3.10)$ & $(3.64)$ & $(2.89)$ & $(3.41)$ \\
\hline $\mathrm{N}$ & 6080 & 6079 & 6080 & 6079 \\
\hline$R-s q$ & 0.066 & 0.038 & 0.07 & 0.04 \\
\hline
\end{tabular}

This table displays the results of the model applied to the subsample that contains only Buy, Strong Buy, Sell, and Strong Sell recommendations. Models 1 and 3 display the results of the model with the dependent variable being the 
SpilloverRatio calculated via the market model, while models 2 and 4 display the results of the model with the dependent variable being the SpilloverRatio calculated via the Fama-French-Carhart 4 factor model. The first two models display the results of the models with AnalystFollowing, while models 3 and 4 display the results of the models with SIZE. The numbers in brackets represent the t-statistics of the coefficients. *,**, and *** represent the level of significance at the $10 \%, 5 \%$, and $1 \%$, respectively. For a detailed explanation of the independent variables, please refer to the description of Table 1.

The coefficient of RECESSION is negative and significant in all four models. This result further supports the informed spillover hypothesis and suggests that the spillover effect of analyst recommendations is lower during recessionary periods.

The coefficient of CORRELATION is positive and significant at the $1 \%$ level in all four models. This result further supports the informed spillover hypothesis and suggests that the greater the correlation of returns between the rated bank and the rival (the more similar they are to each other), the greater the spillover effect. This result also further supports the finding that analyst recommendations in the banking industry are subject to contagion effects (not competitive effects) as the closest rivals of the rated bank are affected the most, and they are affected in the same direction as the rated bank.

The coefficient of EXPERIENCE is negative and significant in all four models. This result suggests that experienced analysts' recommendations are subject to a lesser contagion effect. This result likely indicates that experienced analysts provide more information specific to the rated bank and less about the industry.

The coefficient of RATEDCAR is negative and significant in all four models. This result further supports the informed spillover hypothesis and suggest that the SpilloverRatio is lower for the recommendations that had a greater impact on the rated banks. The coefficient of RATEDCAR ranging from -0.212 to -0.337 shows that the spillover effect of analyst recommendations increases at a decreasing rate relative to the effect that recommendations have on the rated banks. That is, as the CAR01 of the rated bank increases, the CAR01 of rival banks increases as well; however, the CAR01 of the rival bank decreases as a proportion of CAR01 of the rated bank.

The coefficient of POSITIVE is positive and significant at the $1 \%$ level in all four models. This result further supports the informed spillover hypothesis and suggests the positive recommendations are subject to a greater spillover effect. This result is somewhat surprising, as prior evidence would suggest that bank investors are driven by panic and tend to over-react to negative news; however, this result could be due to several reasons. First, negative analyst recommendations are not as dramatic as the events that prior literature has explored (such as bank failures), and therefore they are less likely to cause any panic among depositors and stockholders of other banks. Second, this result could be because a larger number investors can take advantage of a positive recommendation of another bank (any investor can buy the rival's stock); however, only a limited number of investors can take advantage of a negative recommendation of another bank (short the rival's stock).

Table 5 displays the results of the multivariate regression model applied to the subsample that contains recommendations that are an upgrade to a Buy or a Strong Buy, and recommendations that are a downgrade to a Sell or a Strong Sell. Results of Table 5 are similar to the results of Table 4 and further support the results of explained above. They show that the spillover effect is significantly greater for riskier banks (rivals with a higher standard deviation of returns) and during riskier periods (periods with higher VIX). Similarly, the spillover effect is smaller after the enactment of the Dodd-Frank Act, which lowered the risk of the banking industry. Similar to the results of Table 4, the spillover effect is significantly greater for larger banks, banks with larger analyst following, the closest competitors as measured by CORRELATION, and for the positive recommendation. The spillover effect is significantly smaller for recommendations that occur during recessionary periods. In Table 5, the coefficient of SETTLEMENT is positive and significant in 2 of the models. This result suggests that after the Global Analyst Research Settlement, analyst recommendations in the banking industry resulted in greater spillover effects. Hovakimian and Saenyasiri (2010) find that analyst recommendations became less biased and more informative in the post-Settlement period. This result further extends their finding to the 
banking industry and shows that more informative recommendations in the post-Settlement period result in greater spillover effects. Overall, the results of Table 5 further support the informed spillover hypothesis.

\section{TABLE 5}

RESULTS OF THE REGRESSION MODEL APPLIED TO THE SUBSAMPLE THAT CONTAINS ONLY RECOMMENDATIONS THAT ARE UPGRADES TO A BUY/STRONG BUY, OR DOWNGRADES TO A SELL/STRONG SELL

\begin{tabular}{|c|c|c|c|c|}
\hline & Model 1 & Model 2 & Model 3 & Model 4 \\
\hline & \multicolumn{4}{|c|}{ SpilloverRatio SpilloverRatioFFCSpilloverRatioSpilloverRatioFFC } \\
\hline \multirow[t]{2}{*}{ CONSTANT } & $-0.229 * * *$ & $-0.202^{* *}$ & $-0.453^{* * *}$ & $-0.432 * * *$ \\
\hline & $(-2.76)$ & $(-2.06)$ & $(-4.50)$ & $(-3.63)$ \\
\hline \multirow[t]{2}{*}{ STDEV } & $2.762 * * *$ & $3.057 * * *$ & $2.870 * * *$ & $3.163 * * *$ \\
\hline & $(3.75)$ & $(3.50)$ & (3.90) & $(3.62)$ \\
\hline \multirow[t]{2}{*}{ BETA } & 0.0261 & -0.00594 & $0.0311^{*}$ & -0.000851 \\
\hline & $(1.41)$ & $(-0.27)$ & $(1.68)$ & $(-0.04)$ \\
\hline \multirow[t]{2}{*}{ CAPR } & -0.00248 & -0.00496 & -0.0013 & -0.00376 \\
\hline & $(-0.86)$ & $(-1.46)$ & $(-0.45)$ & $(-1.10)$ \\
\hline \multirow[t]{2}{*}{ VIX } & $0.00577 * * *$ & $0.00600^{* * *}$ & $0.00553^{* * *}$ & $0.00576 * * *$ \\
\hline & (5.25) & (4.62) & $(5.02)$ & (4.42) \\
\hline \multirow[t]{2}{*}{ GRAMM } & -0.00342 & -0.0152 & -0.00401 & -0.0157 \\
\hline & $(-0.09)$ & $(-0.35)$ & $(-0.11)$ & $(-0.37)$ \\
\hline \multirow[t]{2}{*}{ DODD } & $-0.170 * * *$ & $-0.175^{* * *}$ & $-0.163 * * *$ & $-0.168 * * *$ \\
\hline & $(-6.83)$ & $(-5.95)$ & $(-6.54)$ & $(-5.69)$ \\
\hline \multirow[t]{2}{*}{ AnalystFollowir } & $0.00749 * * *$ & $0.00785^{* * *}$ & & \\
\hline & (3.54) & $(3.13)$ & & \\
\hline \multirow[t]{2}{*}{ SIZE } & & & $0.0336 * * *$ & $0.0345^{* * *}$ \\
\hline & & & (4.19) & (3.64) \\
\hline \multirow[t]{2}{*}{ NII } & 0.114 & 0.0982 & 0.0464 & 0.03 \\
\hline & (1.47) & $(1.07)$ & $(0.57)$ & $(0.31)$ \\
\hline \multirow[t]{2}{*}{ RECESSION } & $-0.0494 *$ & $-0.103^{* * *}$ & $-0.0550 * *$ & $-0.109 * * *$ \\
\hline & $(-1.89)$ & $(-3.33)$ & $(-2.12)$ & $(-3.55)$ \\
\hline \multirow{2}{*}{ CORRELATION } & $0.334^{* * *}$ & $0.254^{* * *}$ & $0.297 * * *$ & $0.217 * * *$ \\
\hline & $(7.10)$ & $(4.57)$ & $(6.00)$ & $(3.71)$ \\
\hline \multirow[t]{2}{*}{ SETTLEMENT } & 0.0377 & $0.0716^{* *}$ & 0.0395 & $0.0732 * *$ \\
\hline & $(1.43)$ & $(2.29)$ & $(1.50)$ & $(2.35)$ \\
\hline \multirow[t]{2}{*}{ EXPERIENCE } & -0.00228 & -0.00345 & -0.00542 & -0.00669 \\
\hline & $(-0.28)$ & $(-0.36)$ & $(-0.66)$ & $(-0.69)$ \\
\hline \multirow[t]{2}{*}{ NrOfIndustries } & -0.00622 & -0.000539 & -0.00561 & 0.000114 \\
\hline & $(-1.07)$ & $(-0.08)$ & $(-0.97)$ & $(0.02)$ \\
\hline \multirow[t]{2}{*}{ RATEDCAR } & -0.0676 & -0.139 & -0.0711 & -0.139 \\
\hline & $(-0.60)$ & $(-1.01)$ & $(-0.63)$ & $(-1.01)$ \\
\hline \multirow[t]{2}{*}{ POSITIVE } & 0.0363 & $0.0592^{* *}$ & 0.0341 & $0.0563^{*}$ \\
\hline & $(1.41)$ & $(1.97)$ & $(1.32)$ & $(1.87)$ \\
\hline $\mathrm{N}$ & 4232 & 4232 & 4232 & 4232 \\
\hline $\mathrm{R}-\mathrm{sq}$ & 0.063 & 0.034 & 0.064 & 0.035 \\
\hline
\end{tabular}

This table displays the results of the model applied to the subsample that contains only recommendations that are upgrades to a Buy/Strong Buy, or downgrades to a Sell/Strong Sell. Models 1 and 3 display the results of the model with the dependent variable being the SpilloverRatio calculated via the market model, while models 2 and 4 display the results of the model with the dependent variable being the SpilloverRatio calculated via the Fama-FrenchCarhart 4 factor model. The first two models display the results of the models with AnalystFollowing, while models 3 and 4 display the results of the models with SIZE. The numbers in brackets represent the t-statistics of the coefficients. *, **, and $* * *$ represent the level of significance at the $10 \%, 5 \%$, and $1 \%$, respectively. For a detailed explanation of the independent variables, please refer to the description of Table 1. 


\section{ROBUSTNESS TESTS}

To ensure that our results are not contaminated by any recommendations of the rival banks, we also run our models in subsamples that exclude any rival banks which received a recommendation within 5 days (prior or after) of the analyst recommendation. These results are not reported to conserve space; however, they are consistent with the results of Tables 4 and 5.

In addition, to ensure that our results are not contaminated from the information of any prior recommendations of the rated bank, we also run our models in subsamples that exclude any observations in which rated bank received another recommendation in the prior 5 days. These results are not reported to conserve space; however, they are consistent with the results of Tables 4 and 5.

\section{CONCLUSION}

After analyzing the spillover effects of analyst recommendations in the banking industry, we find that positive and negative recommendations elicit a significant spillover effect on the rival banks. The average announcement return of the closest competitors of the rated bank is in the same direction as the announcement return of the rated bank, and it is statistically different from 0 . The announcement return of the rival banks is, on average, between $14 \%$ and $17 \%$ of the magnitude of the announcement return of the rated bank. This finding suggests contagion rather than competitive effects.

In addition, we find that the spillover effect of analyst recommendations is greater for riskier competitors. The spillover effect is also greater for recommendations issued in riskier periods, and regulations that increased the risk of the banking industry increased the spillover effect of analyst recommendations, and vice versa. These results suggest that when faced with greater uncertainty or difficulty in evaluating a bank, investors rely more on the recommendations of other banks. Analyst recommendations also elicit a greater contagion effect in larger rivals and rivals with larger analyst following. These results suggest that investors act upon a recommendation by buying/selling the rival banks that they recognize more or the rivals that are more likely to receive a similar recommendation.

Overall, our findings show that spillover effects are in the same direction as the rated bank's announcement return and that the effects depend on bank characteristics. Thus, we find that spillover effects in the banking industry can be described as informed contagion effects.

\section{ACKNOWLEDGEMENT}

We wish to thank Wm R. McDaniel for his valuable suggestions. Arjan Premti thanks the summer grant program sponsored by the College of Business and Economics at University of Wisconsin Whitewater for research support.

\section{ENDNOTES}

1. For example, see Polonchek, Slovin, and Sushka, 1989; Wansley and Dhillon, 1989; Slovin, Sushka and Polonchek, 1991(a); Slovin, Sushka and Polonchek, 1991(b); Slovin, Sushka and Polonchek, 1992; Filbeck and Mullineaux, 1993; Akhigbe and Madura, 1999(a); Akhigbe and Madura, 1999(b); Filbeck and Mullineaux, 1999; Jackson and Madura, 2004; Cornett, Fayman, Marcus, and Tehranian, 2011).

2. For example, see Grammatikos and Saunders (1990), Aharony and Swary (1996), and Docking, Hirschey and Jones (1997).

3. For example, see DeYoung and Roland, 2001; Cebula, 2010; Geyfman and Yeager, 2009.

4. For example, see Madura and Premti, 2014.

5. For example, see Kim, Lin, and Slovin (1997), and Busse and Green (2002).

6. Loh and Stulz (2011) argue that multiple recommendations on the same day are likely to be triggered by other confounding events. 
7. Some papers have measured the spillover effect by just focusing on the CAR of the rival firm; however, in our case, the use of rival CAR would make it difficult to compare the spillover effect of positive and negative recommendations in a multivariate setting. This is due to the fact that CAR has a different meaning when measuring the spillover effect between positive and negative recommendations: a higher spillover effect would result in a higher CAR for positive recommendation and a lower (more negative) CAR for negative recommendations. SpilloverRatio alleviates these problems because it has the same meaning for both, positive and negative recommendations: a large spillover effect would result in a higher ratio for both positive and negative recommendations.

\section{REFERENCES}

Aharony, J., \& Swary, I. (1996). Additional evidence on the information-based contagion effects of bank failures. Journal of Banking and Finance, 20(1), 57-69.

Akhigbe, A., \& Madura, J. (1999a). Intraindustry effects of bank stock repurchases. Journal of Financial Services Research, 15(1), 23-36.

Akhigbe, A., \& Madura, J. (1999b). Intra-industry signals embedded in bank acquisition announcements. Journal of Banking and Finance, 23(11), 1637-1654.

Akhigbe, A., \& Madura, J. (2001). Why do contagion effects vary among bank failures? Journal of Banking and Finance, 25(4), 657-680.

Akhigbe, A., Madura, J., \& Newman, M. (2006). Industry Effects of Analyst Stock Revisions. The Journal of Financial Research, 29(2), 181-198.

Akhigbe, A., \& Martin, A. D. (2006). Valuation impact of Sarbanes-Oxley: Evidence from disclosure and governance within the financial services industry. Journal of Banking and Finance, 30(3), 989-1006.

Barber, B. M., Lehavy, R., \& Trueman, B. (2010). Ratings changes, ratings levels, and the predictive value of analysts' recommendations. Financial Management, 39(2), 533-553.

Bessler, W., \& Nohel, T. (2000). Asymmetric information, dividend reductions, and contagion effects in bank stock returns. Journal of Banking and Finance, 24(11), 1831-1848.

Boni, L., \& Womack, K. L. (2006). Analysts, industries, and price momentum. Journal of Financial and Quantitative Analysis, 41(1), 85-109.

Bruyckere, V. D., Gerhardt, M., Schepens, G., \& Vennet, R. V. (2013). Bank/sovereign risk spillovers in the European debt crisis. Journal of Banking and Finance, 37(12), 4793-4809.

Busse, J. A., \& Green, T. C. (2002). Market efficiency in real time. Journal of Financial Economics, 65(3), 415-437.

Cliff, M. T. (2007). Do affiliated analysts mean what they say? Financial Management, 36(4), 5-29.

Cornett, M. M., Fayman, A., Marcus, A. J., \& Tehranian, H. (2011). Dividends, maturity, and acquisitions: Evidence from a sample of bank IPOs. Review of Financial Economics, 20(1), 1121.

Cornett M. M., McNutt, J. J., \& Tehranian, H. (2005). Long-term performances of rival banks around bank failures. Journal of Economics and Business, 57(5), 411-432.

DeYoung, R., \& Roland K. P. (2001). Product Mix and Earnings Volatility at Commercial Banks: Evidence from a Degree of Total Leverage Model. Journal of Financial Intermediation, 10(1), 54-84.

Docking, D. S., Hirschey, M., \& Jones, E. (1997). Information and contagion effects of bank loan-loss reserve announcements. Journal of Financial Economics, 43(2), 219-239.

Dungey, M., \& Gajurel, D. (2015). Contagion and banking crisis - international evidence for 20072009. Journal of Banking and Finance, 60, 271-283.

Filbeck, G., \& Mullineaux, D. J. (1993). Regulatory monitoring and the impact of bank holding company dividend changes on equity returns. The Financial Review, 28(3), 403-415.

Filbeck, G., \& Mullineaux, D. J. (1999). Agency costs and dividend payments: The case of bank holding companies. Quarterly Review of Economics and Finance, 39(3), 409-418. 
Francis, J., \& Soffer, L. (1997). The relative informativeness of analysts' stock recommendations and earnings forecast revisions. Journal of Accounting Research, 35(2), 193-211.

Fuller, J., \& Jensen, M. C. (2002) Just Say No to Wall Street: Putting a Stop to the Earnings Game. Journal of Applied Corporate Finance, 14(4), 41-46.

Geyfman, V., \& Yeager, T. J. (2009). On the riskiness of universal banking: Evidence from banks in the investment banking business pre- and post-GLBA. Journal of Money, Credit, and Banking, 41(8), 1649-1670.

Gintschel, A., \& Markov, S. (2004). The effectiveness of regulation FD. Journal of Accounting and Economics, 37(3), 293-314.

Givoly, D., \& Lakonishok, J. (1979). The Information content of financial analysts' forecasts of earnings: Some evidence of semi-strong inefficiency, Journal of Accounting and Economics, 1(3), 165-185.

Grammatikos, T., \& Saunders, A. (1990). Additions to bank loan-loss reserves: Good news or bad news? Journal of Monetary Economics, 25(2), 289-304.

Helwege, J., \& Zhang, G. (2016). Financial Firm Bankruptcy and Contagion, Review of Finance, 20(4), $1321-1362$.

Hertzel, M. G., \& Officer, M. (2012). Industry contagion in loan spreads. Journal of Financial Economics, 103(3), 493-506.

Hovakimian, A., \& Saenyasiri, E. (2010). Conflicts of interest and analyst behavior: Evidence from recent changes in regulation. Financial Analysts Journal, 66(4), 96-107.

Hsu, W., Mamun, A., \& Rose, L. (2010). Size does matter! the intra-industry effect of bank loan ratings. Applied Financial Economics, 20(23), 1807-1818.

Iannotta, G. (2006). Testing for opaqueness in the European banking industry: Evidence from bond credit ratings. Journal of Financial Services Research, 30(3), 287-309.

Ismailescu, I., \& Kazemi, H. (2010). The reaction of emerging market credit default swap spreads to sovereign credit rating changes. Journal of Banking and Finance, 34, 2861-2873.

Jackson, D., \& Madura, J. (2004). Bank profit warnings and signaling. Managerial Finance, 30(9), $20-31$.

Kaufman, G. G. (1994). Bank contagion: A review of the theory and evidence. Journal of Financial Services Research, 8(2), 123-150.

Kim, S. T., Lin, J., \& Slovin, M. B. (1997). Market structure, informed trading, and analysts' recommendations. Journal of Financial and Quantitative Analysis, 32(4), 507-524.

Liu, M. H. (2011). Analysts' incentives to produce industry-level versus firm-specific information. Journal of Financial and Quantitative Analysis, 46(3), 757-784.

Loh, R. K., \& Stulz, R. M. (2011). When are analyst recommendation changes influential? The Review of Financial Studies, 24(2), 593-627.

Loh, R. K., \& Stulz, R. M. (2018). Is Sell-Side Research More Valuable in Bad Times? The Journal of Finance, 73(3), 959-1013.

Madura, J., \& Premti, A. (2014). Impact of the Volcker Rule on Bank Valuations and Risk, Banking and Finance Review, 6(1), 1-24.

Milunovich, G., \& Tan, A. (2013). Testing for contagion in US industry portfolios - a four-factor pricing approach. Applied Financial Economics, 23(1), 15-26.

Morgan, D. P. (2002). Rating banks: Risk and uncertainty in an opaque industry. The American Economic Review, 92(4), 874-888.

Moshirian, F., Ng, D., \& Wu, E. (2009). The value of stock analysts' recommendations: Evidence from emerging markets. International Review of Financial Analysis, 18(1), 74-83.

Piotroski, J. D., \& Roulstone, D. T. (2004). The influence of analysts, institutional investors, and insiders on the incorporation of market, industry, and firm-specific information into stock prices. The Accounting Review, 79(4), 1119-1151.

Polonchek, J., Slovin, M. B., \& Sushka, M. E. (1989). Valuation effects of commercial bank securities offerings: A test of the information hypothesis. Journal of Banking and Finance, 13(3), 443-461.

Premti, A., Garcia-Feijoo, L., \& Madura, J. (2017). Information content of analyst recommendations in the banking industry. International Review of Financial Analysis, 49, 35-47. 
Premti, A., Garcia-Feijoo, L., \& Madura, J. (2018). Bank environment and the investment value of analyst recommendations. Banking and Finance Review, 10(2), 1-34.

Slovin, M. B., Sushka, M. E., \& Polonchek, J. A. (1991a). The information content of multiple seasoned common stock offerings by bank holding companies. Journal of Banking and Finance, 15(3), 633-646.

Slovin, M. B., Sushka, M. E., \& Polonchek, J. A. (1991b). Restructuring transactions by bank holding companies - the valuation effect of sale-and-leasebacks and divestitures. Journal of Banking and Finance, 15(2), 237-255.

Slovin, M. B., Sushka, M. E., \& Polonchek, J. A. (1992). Informational externalities of seasoned equity issues - differences between banks and industrial firms. Journal of Financial Economics, 32(1), 87-102.

Slovin, M. B., Sushka, M. E., \& Polonchek, J. A. (1999). An analysis of contagion and competitive effects at commercial banks. Journal of Financial Economics, 54(2), 197-225.

Wansley, J. W., \& Dhillon, U. S. (1989). Determinants of valuation effects for security offerings of. The Journal of Financial Research, 12(3), 217-233.

Womack, K. L. (1996). Do Brokerage Analysts' Recommendations Have Investment Value? Journal of Finance, 51, 137-167. 